\title{
Repair of Aorto-Right Ventricular Tunnel: A Case Report
}

\author{
Naveen Sheikh \\ Department of Paediatric Cardiology, NUH, Singapore.
}

\begin{abstract}
:
Keywords: Congenital heart disease, AortoRVTunnel $(A R V T)$.

Aorto-ventricular tunnel is a congenital, extracardiac channel which connects the ascending aorta above the sinutubular junction to the cavity of the left, or less commonly, to the right ventricle. Here, I report a successful surgical correction of aorto-right ventricular tunnel with anomalous right coronary artery (RCA) arising from the tunnel in a 42 years old woman diagnosed preoperatively with echocardiography and cardiac catheterization. The operation was performed with cardiopulmonary bypass and hypothermia. Myocardial protection was achieved by antegrade cold blood cardioplegia. The tunnel below the origin of RCA was closed with pericardial patch. Tunnel was closed with mattress suture and running stitches to reduce the diameter and making channel for RCA blood flow. Atrial septal defect was closed by patch. The postoperative course was uneventful except pericardial effusion which was managed conservatively. A follow-up transthoracic echocardiogram demonstrated a securely closed communication without any aortic valve incompetence.
\end{abstract}

(Cardiovasc.j. 2010; 3(1): 98-100)

\section{Introduction:}

Aorto-right ventricular tunnel (ARVT) is a rare congenital communication between one of the aortic sinuses and the right ventricle. ${ }^{1}$ It may be accompanied by coronary abnormalities. I report a successful surgical correction of aorto-right ventricular tunnel with anomalous RCA arising from the tunnel itself, diagnosed preoperatively with echocardiography and cardiac catheterization.

Aorto-ventricular tunnel is a congenital, extracardiac channel which connects the ascending aorta above the sinutubular junction to the cavity of the left, or (less commonly) right ventricle. The exact incidence is unknown, estimates ranging from $0.5 \%$ of fetal cardiac malformations to less than $0.1 \%$ of congenitally malformed hearts in clinico-pathological series. ${ }^{2}$ The etiology of aortoventricular tunnel is uncertain. It appears to result from a combination of maldevelopment of the cushions which give rise to the pulmonary and aortic roots, and abnormal separation of these structures. Aorto-ventricular tunnel must be distinguished from other lesions which cause rapid run-off of blood from the aorta and produce cardiac failure. These include sinus of Valsalva fistula, common arterial trunk with valvar regurgitation, aorto-pulmonary window, ventricular septal defect with aortic regurgitation, persistent patency of the arterial duct, coronary-cameral fistula, valvar aortic stenosis and regurgitation, and cerebral arterio-venous malformation.

A 42 years old woman was admitted in a private hospital, Dhaka, for a work-up of heart murmur known since twenty years. Cardiac cath was done in India in 1994 and diagnosed as rupture sinus of valsalva.

Results of physical examination were within normal limits, except for the murmur. A continuous grade $3 / 6$ heart murmur was best heard along the right upper sternal border. Chest X-ray showed cardiomegaly with increased pulmonary arterial markings. Electrocardiogram showed sinus rhythm, right heart overload and right bundle branch block.

Echocardiogram revealed a large ASD and enlargement of the RA and right ventricle.She had mild to moderate pulmonary hypertension. Aortic valve was normal without regurgitation and preserved left ventricular function. There was an aneurysmatically dilated communication to the right of the aorta between the ascending aorta and right ventricle.

Cardiac catheterization revealed a runoff of contrast material from the ascending aorta through the tunnel into the RV. Root angiogram

Address of Correspondence : Dr. Naveen Sheikh, Department of Paediatric Cardiology, NUH, Singapore. 
revealed a large tunnel originating from the right sinus of Valsalva and terminating in the RV (figure:1). Coronary angiography revealed the right coronary artery arising from right wall of tunnel. A selective injection of the tunnel showed RCA arising from the tunnel. Contrast medium was shunting through a small perforation at the tip of tunnel and filling RV during diastole. The pulmonary/systemic blood flow ratio was estimated at $1.36: 1$.

The operation was performed with cardiopulmonary bypass and hypothermia. Myocardial protection was achieved by antegrade cold blood cardioplegia. After the aorta was crossclamped, the dilated tunnel was incised longitudinally. Right coronary artery was arising from right lateral wall of tunnel over the right ventricle. One opening was clearly identified in the RV. The tunnel below the origin of RCA was closed with pericardial patch. Tunnel was closed with mattress suture and running stitches to reduce the diameter and making channel for $\mathrm{RCA}$ blood flow. Atrial septal defect was closed by patch. The postoperative course was uneventful except pericardial effusion which was managed conservatively. A follow-up transthoracic echocardiogram demonstrated a securely closed

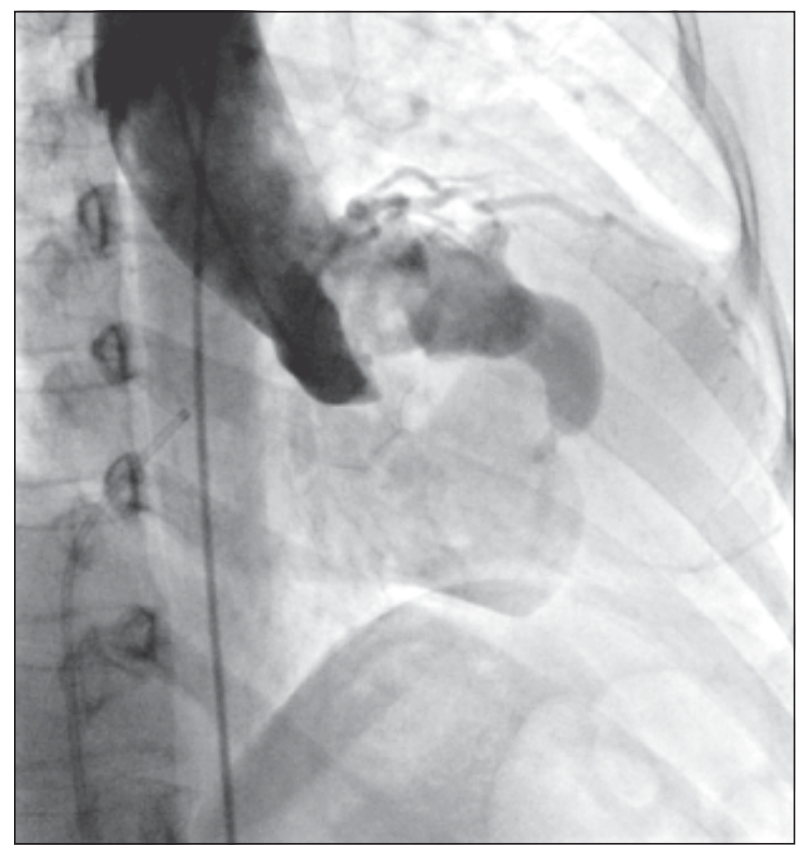

Fig.-1: Root angiogram showing a large tunnel originating from the right sinus of Valsalva and terminating in the $R V$. communication without any aortic valve incompetence.

\section{Discussion:}

An aorto-ventricular tunnel is an extracardiac channel which connects the ascending aorta above the sinutubular junction to the cavity of the left or right ventricle. Recognizing that the tunnel may extend to either the left or the right ventricular cavity, the more general designation "aortoventricular tunnels" has recently been applied to this group of malformations. ${ }^{3}$ The incidence of aorto-left ventricular tunnel has been variably estimated to be around $0.1 \%$ of congenitally malformed hearts from review of clinical and pathological material. ${ }^{4} 0.05 \%$ among patients undergoing cardiac catheterization during a 35-year interval at the Children's Hospital in Boston and $0.46 \%$ of cardiac malformations identified by fetal echocardiography. ${ }^{5}$ Occasional patients present with an asymptomatic heart murmur and cardiac enlargement, but most suffer heart failure in the first year of life. Surgical treatment should be done after diagnosis because the patency of the tunnel might be predisposed to some complications such as cardiac failure, endocarditis, aneurysm formation or rupture.Optimal management of symptomatic aorto-ventricular tunnel consists of diagnosis by echocardiography, complimented with cardiac catheterization as needed to elucidate coronary arterial origins or associated defects, and prompt surgical repair. It differs from a ruptured sinus of Valsalva aneurysm (sinus of Valsalva fistula) in having its vascular orifice in the tubular aorta, rather than a sinus of the aortic valve, and in passing outside the heart into the tissue plane between the muscular subpulmonary infundibulum and the aortic valvar sinuses. ${ }^{6}$ The aortic opening of most tunnels lies above the right coronary sinus of Valsalva. In our case, the tunnel communicated with the right ventricle. The ostium of a coronary artery may lie within an aorto-ventricular tunnel, and absence of the origin (atresia) of the left ${ }^{6}$ or right ${ }^{3}$ have both been observed with this anomaly. In one reported case, there was a fistula between the right coronary artery and the distal segment of a tunnel to the left ventricle ${ }^{7}$ Associated lesions of the aortic valve occur in about $20 \%$ of patients, ranging from two-leaflet valves without obstruction $^{1,2}$ to severe dysplasia or atresia $7,8,9$ 
In addition, older patients may acquire leaflet perforation $^{10,11}$ or aortic incompetence ${ }^{12}$ as the result of hydrodynamic trauma to the unsupported right coronary cusp or progressive aortic .The etiology of aorto-ventricular tunnel is uncertain. It appears to result from a combination of maldevelopment of the cushions which give rise to the pulmonary and aortic roots, and abnormal separation of these structures. Echocardiography is the diagnostic investigation of choice. Antenatal diagnosis by fetal echocardiography is reliable after 18 weeks gestation. Magnetic resonance angiography also has been used to demonstrate tunnels to the left and right ventricles but is not widely available in clinical practice. Cardiac catheterization with angiography is now indicated only when associated lesions or coronary arterial origins cannot be evaluated with certainty on noninvasive studies. Aorto-ventricular tunnel must be distinguished from other lesions which cause rapid run-off of blood from the aorta and produce cardiac failure. In general, surgical correction of a tunnel carrying significant blood flow should be undertaken without delay, even in asymptomatic patients. All patients require life-long follow-up for recurrence of the tunnel, aortic valve incompetence, left ventricular function, and aneurysmal enlargement of the ascending aorta. In general, surgical correction of a tunnel carrying significant blood flow should be undertaken without delay, even in asymptomatic patients, as only those repaired in the first six months of life have been shown to have subsequent normalization of left ventricular size and function Associated lesions of the aortic valve occur in about $20 \%$ of patients, ranging from two-leaflet valves without obstruction $^{1,2}$ to severe dysplasia or atresia $7,8,13,16$ In addition, older patients may acquire leaflet perforation $^{10,11}$ or aortic incompetence ${ }^{14}$ as the result of hydrodynamic trauma to the unsupported right coronary cusp or progressive aortic dilatation. Repair consists of closing the tunnel such that the aortic valve is supported, the coronary circulation is not compromised, and left or right ventricular outflow obstruction is prevented or relieved. Transcatheter closure of a tunnel to the left ventricle with an Amplatzer duct occluder has been reported in two patients, but attempted coil closure of one to the right ventricle was not effective. ${ }^{14}$

\section{References:}

1. Roxane McKay Orphanet Journal of Rare Diseases 2007; $2: 41$

2. Okoroma EO, Perry LW, Scott LP III, McClenathan JE. Aortico-left ventricular tunnel. Clinical profile, diagnostic features and surgical considerations. J Thorac Cardiovasc Surg 1976; 71:238-44.

3. Sommerville J, English T, Ross DN. Aorto-left ventricular tunnel. Clinical features and surgical management. Br Heart J 1974; 36:321-8.

4. Okoroma EO, Perry LW, Scott LP III, McClenathan JE. Aortico-left ventricular tunnel. Clinical profile, diagnostic features and surgical considerations. J Thorac Cardiovasc Surg 1976; 71:238-44. .

5. Martins JD, Sherwood MC, Mayer JE Jr, Keane JF. Aortico-left ventricular tunnel: 35 - year experience. $J$ Am Coll Cardiol 2004; 44:446-50.

6. Saylam A, Tuncali T, Ikizler C, Aytaç A. Aorto-right ventricular tunnel. A new concept in congenital cardiac malformations. Ann Thorac Surg 1974; 18:634-7.

7. Cook AC, Fagg NKL, Ho SY, Groves AMM, Sharland GK, Anderson RH, Allen LD: Echocardiographicanatomical correlations in aorto-left ventricular tunnel. Br Heart J 1995, 74:443-8.

8. Bitar FF, Smith FC, Kavey R-EW, Kveselis DA, Byrum CJ, Brandt B, Gaum WE: Aortico-left ventricular tunnel with aortic atresia in the newborn. Am Heart $J$ 1993; 126:1480-2.

9. Guyton RA, Michalik RE, McIntyre AB, Plauth WH Jr, Nugent EW, Hatcher CR Jr, Williams WH: Aortic atresia and aortico-left ventricular tunnel: successful surgical management by Konno aortoventriculoplasty in a neonate. J Thorac Cardiovasc Surg 1986; 92:1099-1105

10. Meldrum-Hanna W, Schroff R, Ross DN: Aortico-left ventricular tunnel: late follow-up. Ann Thorac Surg 1986; 42:304-6.

11. Warnke H, Bartel J, Blumenthal-Barby Ch: Aorticoventricular tunnel. Thorac Cardiovasc Surg 1988; 36:86-8.

12. Akalin H, Erol Ç, Oral D, Çorapçioglu T, Uçanok K, Özyurda Ü, Ulusoy V: Aortico-left ventricular tunnel: successful diagnostic and surgical approach to the oldest patient in the literature. J Thorac Cardiovasc Surg 1989; 97:804-5.

13. Sousa-Uva M, Touchot A, Fermont L, Piot D, Delezoide AL, Serraf A, Lacour-Gayet F, Roussin R, Bruniaux J, Planché C: Aortico-left ventricular tunnel in fetuses and infants. Ann Thorac Surg 1996; 61:1805-10

14. Hruda J, Hazekamp MG, Sobotka-Plojhar MA, Ottenkamp J: Repair of aorto-right ventricular tunnel with pulmonary stenosis and an anomalous origin of the left coronary artery. Eur J Cardiothorac Surg 2002; $21: 1123-5$. 